\title{
Oxygen-free precursor for chemical vapor deposition of gold films: thermal properties and decomposition mechanism
}

\author{
Asiya E. Turgambaeva • Galina Zharkova - Petr Semyannikov • Vladislav V. Krisyuk • \\ Tatyana Koretskaya $\cdot$ Sergey Trubin $•$ Boris Kuchumov $\cdot$ Igor Igumenov
}

Published online: 9 September 2011

(C) The Author(s) 2011. This article is published with open access at Springerlink.com

\begin{abstract}
Thermal properties of oxygen-, phosphorus-, and halogen-free dimethylgold(III) diethyldithiocarbamate complex $\left(\mathrm{CH}_{3}\right)_{2} \mathrm{AuS}_{2} \mathrm{CN}\left(\mathrm{C}_{2} \mathrm{H}_{5}\right)_{2}$ (gold, dimethyl(diethylcarbamodithioato -S, $\mathrm{S}^{\prime}$ )-) having excellent storage stability and the mechanism of its decomposition to elemental gold were studied. Saturated vapor pressure was found to be $\sim 10^{-3}$ $10^{-1}$ Torr at $50-90^{\circ} \mathrm{C}$. Decomposition of the vapor on the surface starts at $T=210^{\circ} \mathrm{C}$. The temperature dependence of gas phase composition was studied using the original mass spectrometric technique, it was established that the decomposition of the compound on the surface in vacuum follows three main pathways. Two of them result in the formation of elemental gold, saturated $\mathrm{C} 2-\mathrm{C} 4$ alkanes and (1) protonated ligand or (2) methylated ligand. The third one results in elemental gold and gaseous products: $\mathrm{C} 2-\mathrm{C} 3$ alkylmercaptanes and $\mathrm{CH}_{3} \mathrm{SCN}\left(\mathrm{C}_{2} \mathrm{H}_{5}\right)_{2}$. The formation of gold as a sole solid product within the temperature range $210-240^{\circ} \mathrm{C}$ was confirmed by X-ray photoelectron spectroscopy analysis. It was shown that the compound exhibits the best combination of volatility, thermal, and storage stability among volatile organogold complexes and thus it may be a promising precursor for obtaining gold films by chemical vapor deposition.
\end{abstract}

Keywords Gold films · Metallorganic CVD · Dimethylgold diethyldithiocarbamate - Volatile complex of dimethylgold . Thermolysis mechanism . Thermal properties

Electronic supplementary material The online version of this article (doi:10.1007/s13404-011-0026-5) contains supplementary material, which is available to authorized users.

A. E. Turgambaeva $\cdot$ G. Zharkova $\cdot$ P. Semyannikov $\cdot$

V. V. Krisyuk $(\bowtie) \cdot$ T. Koretskaya $\cdot$ S. Trubin $\cdot$ B. Kuchumov $\cdot$

I. Igumenov

Nikolaev Institute of Inorganic Chemistry SB RAS,

Pr. Lavrentiev 3,

Novosibirsk 630090, Russia

e-mail:kvv@niic.nsc.ru

\section{Introduction}

Gold thin films and nanostructures have numerous valuable applications in microelectronic devices [1-4], optical devices $[5,6]$, catalysis $[7,8]$, etc. To manufacture goldcontaining films, chemical vapor deposition (CVD) is a promising method allowing preparation of conformal coatings on different types of substrates with effective control of morphology of the forming films [9-13]. Thermolysis of the vapors of complex compounds of the metal with organic ligands on a substrate underlies the method of metallorganic CVD. Thus, thermal properties, namely volatility and thermal stability, play a critical role in the correct choice of the source compound (precursor) for this technique. Various volatile gold compounds have been investigated as gold CVD precursors. These mainly include substituted phosphine complexes of alkylgold(I) [13, 14], trifluorophosphine gold(I) chloride [15], dimethylgold (III) derivatives of $\beta$-diketonates [10], carboxylates [11], and salicylaldimines [12]. Dimethylgold(III) $\beta$-diketonate derivatives have been the objects of our investigations for a long time: we developed synthesis techniques, established crystal structures, and evaluated the thermal properties of the compounds [16-19]. Dimeric dimethylgold(III) carboxylates are usually more stable but less volatile and produce corrosive carboxylic acids under decomposition. The effect of the substituent in the carboxylate ligand on the thermal properties and on the volatility of dimethylgold(III) carboxylates was demonstrated [20]. Dimethylgold(III) salicylaldimines are air-, moisture-, and light-sensitive compounds and exhibit considerably lower thermal stability and volatility. The products of thermal decomposition of a number of compounds were studied by mass spectrometric techniques $[12,16,20]$. As to gold(I) compounds [13, 15], they require special synthesis and handling conditions. Though there are some examples of using the aforementioned compounds for film deposition, their thermal properties leave 
much to be desired. In special cases, e.g., co-deposition of metallic films, there is a great need to find an oxygen- and halogen-free precursor. Therefore, the search for gold CVD precursors containing no elements that are inclined to form undesirable impurities, and possessing improved thermal properties, is of great importance.

Here, we present the results obtained in the investigation of the thermal behavior of dimethylgold(III) diethyldithiocarbamate (gold, dimethyl(diethylcarbamodithioato-S, $\mathrm{S}^{\prime}$ )-) $\left(\mathrm{CH}_{3}\right)_{2} \mathrm{AuS}_{2} \mathrm{CN}\left(\mathrm{C}_{2} \mathrm{H}_{5}\right)_{2}, \mathbf{1}$ (Scheme 1) and the mechanism of its heterogeneous decomposition to elemental gold. In contrast to other known dimethylgold(III) precursors, this compound does not contain oxygen and halogen. In comparison with gold(I) precursors, it is free of phosphorus and halogen and does not require special dry conditions for synthesis and handling because it is light stable and air stable. Aiming to compare its potential as CVD precursor, we consider thermal properties of four other volatile compounds of noble metals having similar planar square structure/geometry: $\beta$-diketonate complexes of dimethylgold(III) $(2,3)$ and diethyldithiocarbamate complexes of platinum(II) (4), and palladium(II) (5) forming metal upon decomposition (Scheme 1).

We used both the traditional approach to study thermal behavior in the solid phase with the help of thermogravimetry (TG)-differential thermal analysis (DTA) technique and an original technique based on mass spectrometer (MS) to monitor the changes in the composition of the gas phase during the programmed heating of the compound vapor. In this way, we obtained the information concerning the temperature range and composition of the gas phase while vaporizing the compound. We have also determined the temperature points corresponding to the onset and the maximum rate of compound vapor decomposition along with the identification of gaseous products. All these data provide a deeper insight into the reactivity and thermal stability of precursors and thus contribute to the optimization of the deposition process.

\section{Experimental}

Synthesis

Compound 1, which is a monomeric complex with $\mathrm{AuC}_{2} \mathrm{~S}_{2}$ coordination core, was synthesized by the reaction of heptane solution of $\left[\left(\mathrm{CH}_{3}\right)_{2} \mathrm{AuI}\right]_{2}$ and ethanol solution of $\left(\mathrm{C}_{2} \mathrm{H}_{5}\right)_{2} \mathrm{NCS}_{2} \mathrm{Na}^{*} 3 \mathrm{H}_{2} \mathrm{O}$ (with reagents ratio $1: 1.1)$. The isolated product was purified by vacuum sublimation $\left(P=10^{-2}\right.$ Torr at $\left.150^{\circ} \mathrm{C}\right)$. The yield of the product was $95 \%$. Light yellow crystals $\left(\mathrm{Mp} .38^{\circ} \mathrm{C}\right.$, determined using Kofler apparatus) are well soluble in common organic solvents. More details on the synthesis and the results of crystal structure study were reported in our previous paper [21].

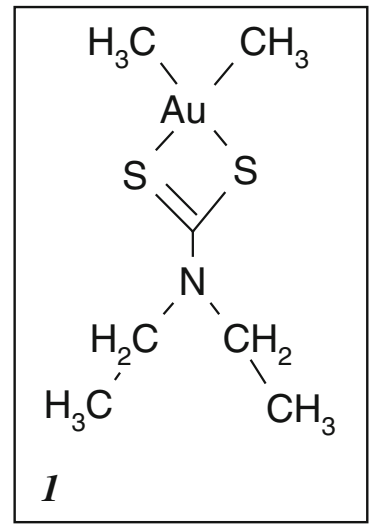

1 - $\left(\mathrm{CH}_{3}\right)_{2} \mathrm{AuS}_{2} \mathrm{CN}\left(\mathrm{C}_{2} \mathrm{H}_{5}\right)_{2}$, dimethylgold(III) diethyldithiocarbamate;

2 - $\left(\mathrm{CH}_{3}\right)_{2} \mathrm{AuCH}_{3} \mathrm{C}(\mathrm{O}) \mathrm{CHC}(\mathrm{O}) \mathrm{CH}_{3}$, dimethylgold(III) acetylacetonate;

3 - $\left(\mathrm{CH}_{3}\right)_{2} \mathrm{AuC}\left(\mathrm{CH}_{3}\right)_{3} \mathrm{C}(\mathrm{O}) \mathrm{CHC}(\mathrm{O}) \mathrm{C}\left(\mathrm{CH}_{3}\right)_{3}$, dimethylgold(III) dipivaloylmethanate;

4 - $\mathrm{Pt}\left[\mathrm{S}_{2} \mathrm{CN}\left(\mathrm{C}_{2} \mathrm{H}_{5}\right)_{2}\right]_{2}$, platinum(II) diethyldithiocarbamate;

5 - $\mathrm{Pd}\left[\mathrm{S}_{2} \mathrm{CN}\left(\mathrm{C}_{2} \mathrm{H}_{5}\right)_{2}\right]_{2}$, palladium(II) diethyldithiocarbamate

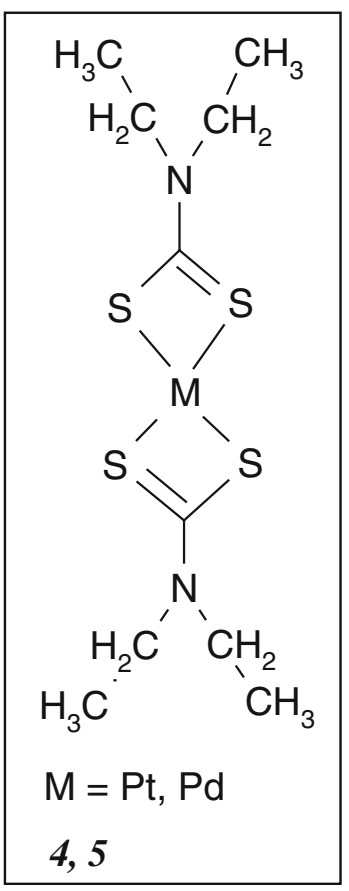

dimethylgold(III) dipivaloylmethanate; 4- $\mathrm{Pt}\left[\mathrm{S}_{2} \mathrm{CN}\left(\mathrm{C}_{2} \mathrm{H}_{5}\right)_{2}\right]_{2}$, platinum(II) diethyldithiocarbamate; and 5- $\mathrm{Pd}\left[\mathrm{S}_{2} \mathrm{CN}\left(\mathrm{C}_{2} \mathrm{H}_{5}\right)_{2}\right]_{2}$, palladium (II) diethyldithiocarbamate 


\section{TG-DTA study}

The thermal properties of $\mathbf{1}$ in the solid phase were studied by means of TG using thermobalance TG 209 F1 Iris ${ }^{\circledR}$ (NETZSCH). The measurements at atmospheric pressure were performed in helium flow $(30-40 \mathrm{~mL} / \mathrm{min})$ with the heating rate of $10^{\circ} \mathrm{C} / \mathrm{min}$ within the temperature range 50 $350^{\circ} \mathrm{C}$; a standard open crucible was used.

\section{Vapor pressure measurement}

Measurement of saturated vapor pressure of $\mathbf{1}$ was performed using the Knudsen effusion method with mass spectrometric recording of gas phase composition within the temperature range of $50-90^{\circ} \mathrm{C}$. The technique and the procedure were described in detail in [22].

Investigation of the mechanism of thermal decomposition

Thermal decomposition was studied using the experimental setup consisting of the evaporator and a temperature-controlled cell ("reactor") built into the time-of-flight mass spectrometer (TOF MS). TOF MS was used to analyze the gas phase. Ionization was performed by the electrons with energy $c a .70 \mathrm{eV}$. The system was described in detail in [23]. Data collection and processing were performed using the National Instruments Corp. hardware and software. The following procedure was used. The compound in a glass ampoule was kept at $90^{\circ} \mathrm{C}$ under dynamic vacuum conditions. The vapor of the compound passed into the reactor, which was heated from $105^{\circ} \mathrm{C}$ to $300^{\circ} \mathrm{C}$ with a rate of $5 \% \mathrm{~min}$. The reaction mixture entered directly the MS ion source through the $0.2 \mathrm{~mm}$ effusive orifice of the reactor. To characterize the gas phase composition, full-range mass spectra were recorded each $10^{\circ}$ during the reactor heating.

CVD experiments and films characterization

Preliminary experiments on nanostructured gold films CVD were conducted in a stagnant flow, vertical cold wall reactor. The deposition pressure was 10 Torr, argon was used as a carrier gas; the temperature of the substrates (oxidized silicon) was within the range 210 $240^{\circ} \mathrm{C}$. The precursor evaporator was maintained at $90^{\circ} \mathrm{C}$.

The films were submitted to X-ray photoelectron spectroscopy (XPS) on SPECS (Germany) instrument. The photoelectron spectra were excited using monochromatized $\mathrm{Al} \mathrm{K} \alpha$ radiation $(h \nu=1486.74 \mathrm{eV})$ with the source power of $200 \mathrm{~W}$ and X-ray beam diameter of $6 \mathrm{~mm}$. Analyses were performed before and after etching the superficial layers of the film with $\mathrm{Ar}^{+}$ions.

\section{Results and discussion}

Mass spectrum

Mass spectrometry was used to identify the compound, to evaluate its vaporization stability and to study the gas phase under thermal decomposition. $\mathbf{1}$ has a good vaporization stability, which is confirmed by the fact that there are no changes in the mass spectrum (it is recovered completely) under repeated heating (up to $100^{\circ} \mathrm{C}$ ) and cooling cycles for the compound in the evacuated evaporator.

The analysis of the mass spectrum showed that $\mathbf{1}$ is monomeric in the gas phase like in the solid: there are no peaks above $\mathrm{m} / \mathrm{z} 375$ corresponding to molecular ion $\left[\left(\mathrm{CH}_{3}\right)_{2} \mathrm{AuS}_{2} \mathrm{CN}\left(\mathrm{C}_{2} \mathrm{H}_{5}\right)_{2}\right]^{+}$. The most intensive Aucontaining peak $\left[\mathrm{AuS}_{2} \mathrm{CN}\left(\mathrm{C}_{2} \mathrm{H}_{5}\right)_{2}\right]^{+}$selected for monitoring of the precursor behavior is formed due to the elimination of methyl groups from the molecular ion. Further fragmentation of this ion proceeds with formation of Au-containing ions $\left[\mathrm{AuS}_{2} \mathrm{C}\right]^{+},[\mathrm{AuSC}]^{+}$, etc. This is characteristic of other metal diethyldithiocarbamates [24]. Another way results in the appearance of radical ligand $\left[\mathrm{S}_{2} \mathrm{CN}\left(\mathrm{C}_{2} \mathrm{H}_{5}\right)_{2}\right]^{+}$and its fragments in the mass spectrum.

\section{Thermal stability and volatility}

Investigation of the behavior of $\mathbf{1}$ in the solid state under heating in an open crucible in the inert environment showed that vaporization occurred cleanly in one step: $97.9 \%$ mass loss at $T=240^{\circ} \mathrm{C}$ was observed on the TG curve, while the residual masses for the compared compounds were within the range from $12 \%$ for 4 to $56 \%$ for 2 (Fig. 1). There was no exothermic peak on the DTA curve but only an endothermic one corresponding to melting was recorded at $48^{\circ} \mathrm{C}$. These results indicate that $\mathbf{1}$ is quite stable and

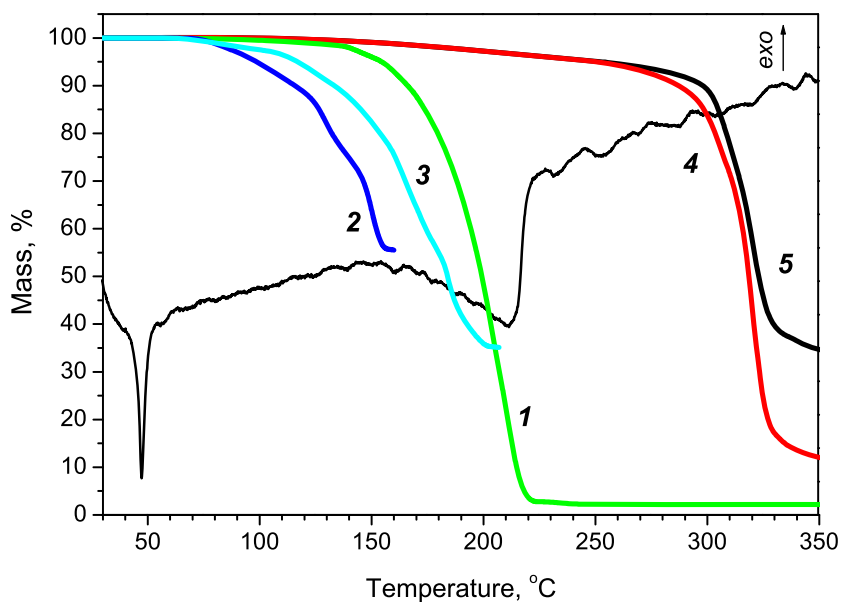

Fig. 1 TG-DTA data for 1 and TG curves for 2, 3 and 4, 5 [25] (helium flow, ramp rate $10 \% \mathrm{~min}$ ) for comparison 
Fig. 2 Temperature dependence of saturated vapor pressure for $1 ; 2,3[10]$ and $4,5[25]$ (helium flow, ramp rate $10^{\circ} / \mathrm{min}$ ) for comparison

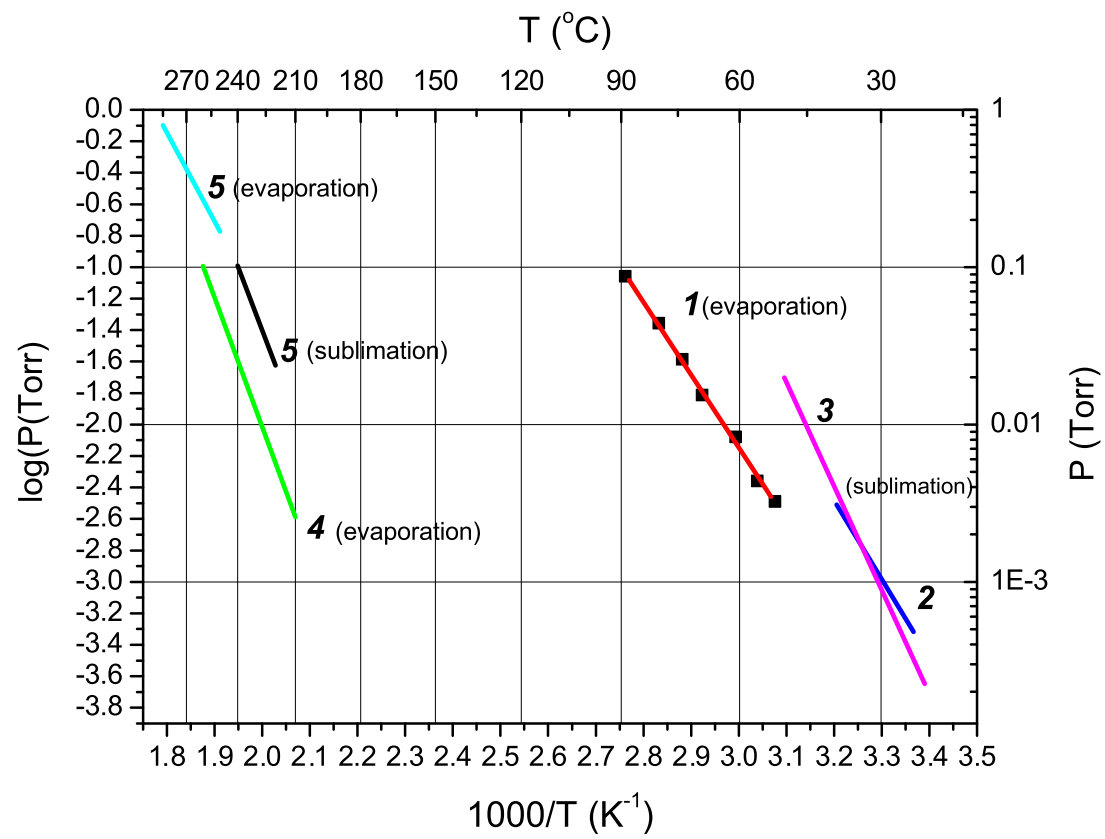

volatile, i.e., it is evaporated without decomposition at relatively low temperatures.

To identify the decomposition onset, we used a semiclosed crucible to reduce evaporation rate and achieve decomposition. Under these conditions, in addition to the endothermic peak corresponding to melting, we also observed an exothermic peak at $225^{\circ} \mathrm{C}$ (not shown), corresponding to decomposition onset. Decomposition onset determined from DTA for $\mathbf{2 , 3}$, and $\mathbf{4 , 5}$ was found to be $145^{\circ} \mathrm{C}, 200^{\circ} \mathrm{C}$ [16] and $300^{\circ} \mathrm{C}, 335^{\circ} \mathrm{C}$ [25], respectively. Thus it may be concluded that 1 demonstrates the best combination of volatility and thermal stability among the considered metallorganic complexes. In addition, it passes into the gas phase from the melt (i.e., evaporation takes place), which is preferable for CVD techniques because the use of the precursor in the liquid state allows precise stoichiometry control in the precursor feeding line.

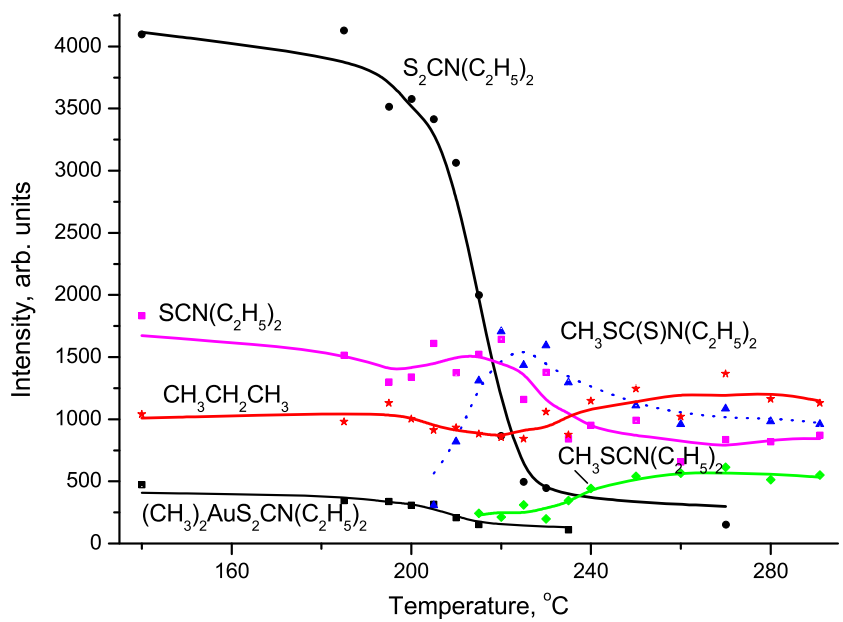

Fig. 3 Temperature dependences of the gas phase composition for the decomposition of 1 in vacuum
The data obtained in the TG studies of the volatility of the compound were supported by the direct measurement of the temperature dependence of vapor pressure. The dependence of saturated vapor pressure on temperature is expressed by the Clapeiron-Clausius equation as $\log (P(T))=-A / T+B$, where $A=\Delta H^{\circ}{ }_{T} / R, B=\Delta S^{\mathrm{o}}$ ${ }_{T} / R$ and $\Delta H^{\mathrm{o}} T$ is enthalpy, $\Delta S^{\mathrm{o}}{ }_{T}$ is entropy of evaporation at the mean temperature $T$ and $R$ is an ideal gas constant. The following data were obtained for $\mathbf{1}$ :

$$
\begin{aligned}
& \log (P(\text { Torr }))=11.7 \pm 0.3-(4,617 \pm 95) / T, \Delta H \\
& \quad=88.3 \pm 1.8 \mathrm{~kJ} / \mathrm{mol}, \Delta S=168.7 \pm 5.3 \mathrm{~J} /(\mathrm{mol} \times \mathrm{K}) .
\end{aligned}
$$

The $P(T)$ dependence is plotted in Fig. 2. One can see that 1 exhibits the best volatility among diethyldithiocarbamates, its volatility is quite comparable with that of the $\beta$-diketonate complexes.

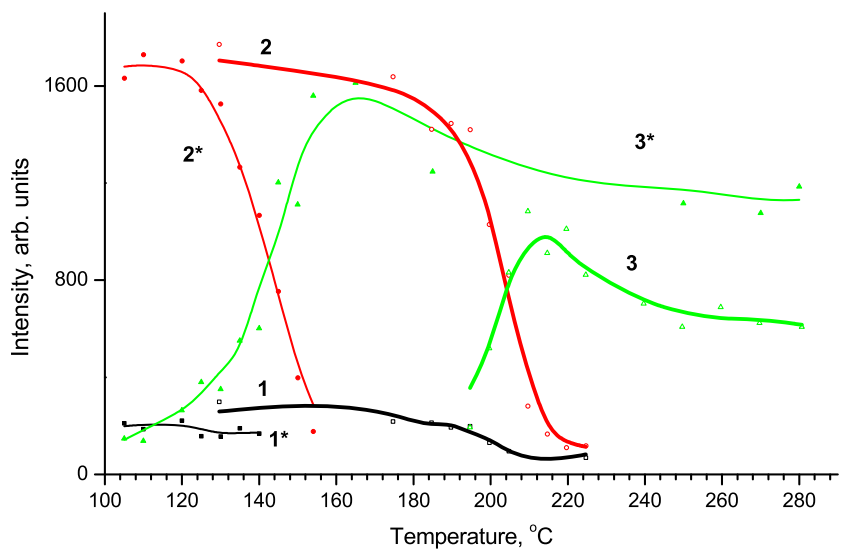

Fig. 4 Comparison of temperature dependences of the gas phase composition of 1 for the direct and reverse (asterisk) temperature course: $1\left(\mathrm{CH}_{3}\right)_{2} \mathrm{AuS}_{2} \mathrm{CN}\left(\mathrm{C}_{2} \mathrm{H}_{5}\right)_{2}, 2 \mathrm{~S}_{2} \mathrm{CN}\left(\mathrm{C}_{2} \mathrm{H}_{5}\right)_{2}, 3 \mathrm{CH}_{3} \mathrm{~S}_{2} \mathrm{CN}\left(\mathrm{C}_{2} \mathrm{H}_{5}\right)_{2}$ 
Scheme 2 Reasonable mechanism suggested for a continuously growing film of gold

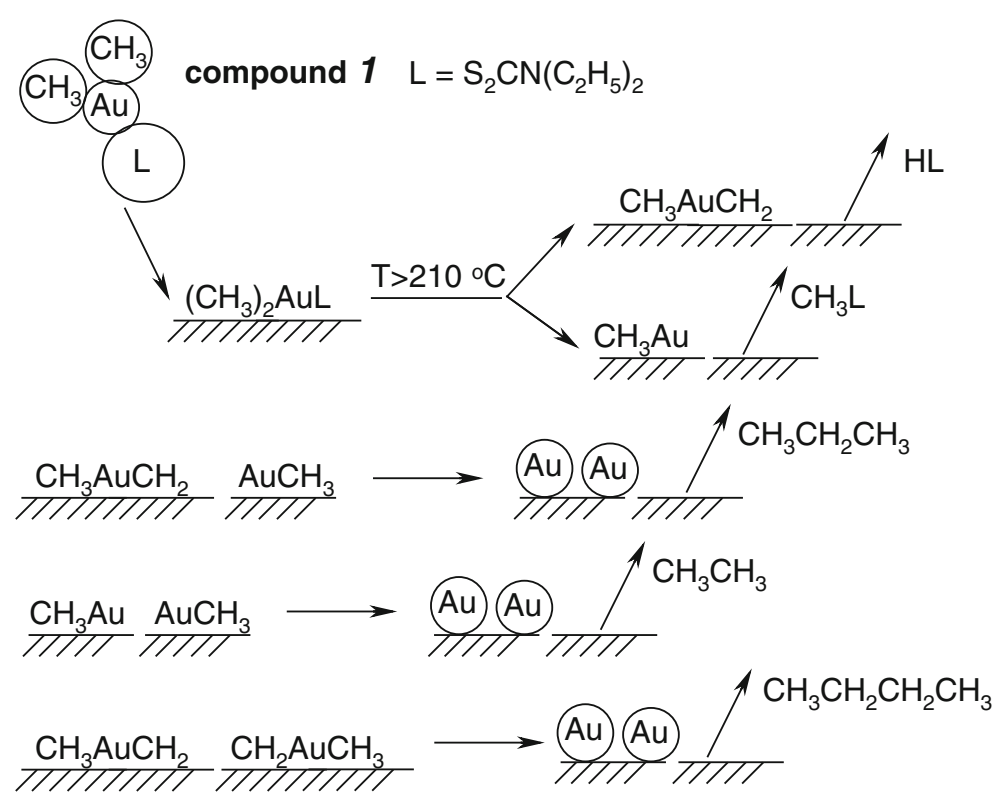

The mechanism of thermal decomposition

Due to the very low-pressure operating conditions in a hot wall reactor, any conversions of the compound vapor occurred on the reactor walls. All the experiments were performed with the surface formed by the solid decomposition products. For this purpose, the precursor vapor was passed through the reactor at $300^{\circ} \mathrm{C}$ before the experiments. The time from the moment when a particle left the reactor to the moment when it was ionized did not exceed a
Scheme 3 A new gaseous product is observed represented by the ion peak at $\mathrm{m} / \mathrm{z} 131$ which is attributed to $\left[\left(\mathrm{CH}_{3}\right) \mathrm{SCN}\right.$ $\left.\left(\mathrm{C}_{2} \mathrm{H}_{5}\right)_{2}\right]^{+}$

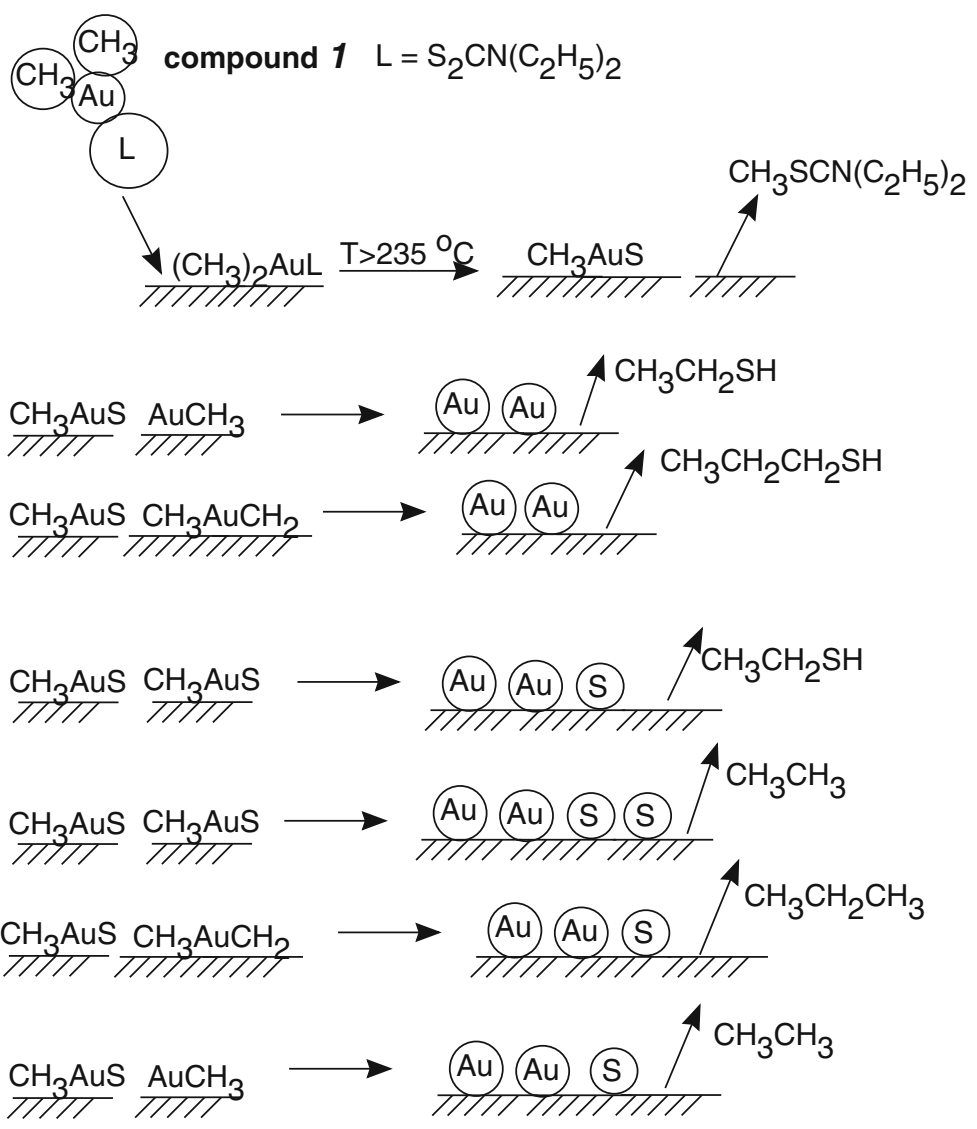


millisecond. These conditions present the advantage of unambiguous determination of the composition of the resulting gas phase without any interference due to the recombination of the investigated species either in the deposition chamber or in the sampling system, i.e., the primary gaseous products of decomposition are recorded.

The results of the experiments were obtained as temperature dependences of intensities of ion peaks derived from the fullrange mass spectra. The dependences for selected ion peaks characterizing the gas phase upon decomposition in vacuum are shown in Fig. 3. It should be noted that the intensity of the peak is proportional to the concentration (partial pressure) of the species in the reaction mixture. Examination of the changes in the mass spectrum at different temperatures allowed us to reveal the gaseous products formed in the thermal decomposition of the compound vapor. Upon reaching the decomposition onset temperature, the intensity of the ion peaks $\left[\mathrm{S}_{2} \mathrm{CN}\left(\mathrm{C}_{2} \mathrm{H}_{5}\right)_{2}\right]^{+}$and $\left[\left(\mathrm{CH}_{3}\right)_{2} \mathrm{AuS}_{2} \mathrm{CN}\left(\mathrm{C}_{2} \mathrm{H}_{5}\right)_{2}\right]^{+}$ related to the source compound 1 decrease while the intensities of ion peaks corresponding to the products increase. Thus, the vapor of 1 starts to decompose at $T=210 \pm 10^{\circ} \mathrm{C}$. This decomposition onset temperature is considerably higher than that for the vapor of dimethylgold(III) $\beta$-diketonate derivatives: $92^{\circ} \mathrm{C}$ and $125^{\circ} \mathrm{C}$ for $\mathbf{2}$ and $\mathbf{3}$, respectively [16]. A feature of compound $\mathbf{1}$ is a narrow range between the temperature points of decomposition onset and the maximum decomposition degree $\left(240^{\circ} \mathrm{C}\right.$, intensity of Au-containing peaks is close to the background value). Another notable feature is the temperature-dependence profile of the gas phase composition upon return temperature course. One can see in Fig. 4 that the curves corresponding to heating the reactor till $300^{\circ} \mathrm{C}$ and the return process have similar appearance; however, there is a considerable shift $\left(60^{\circ} \mathrm{C}\right)$ to lower temperatures during the return. We believe that it is due to the catalysis by freshly formed gold nanofilm.

The analysis of the temperature dependence of mass spectra and the comparison of the mass spectra with the reference mass spectra from NIST Chemistry WebBook (http://webbook.nist. gov/chemistry) allowed us to reveal that the protonated ligand $^{1}$ (diethyldithiocarbamic acid, $\mathrm{HS}_{2} \mathrm{CN}\left(\mathrm{C}_{2} \mathrm{H}_{5}\right)_{2}$ ) and the methylated ligand (methyl diethyldithiocarbamate, $\left.\mathrm{CH}_{3} \mathrm{~S}_{2} \mathrm{CN}\left(\mathrm{C}_{2} \mathrm{H}_{5}\right)_{2}\right)$ are the major gaseous products of decomposition.

In spite of our inability to identify any intermediate decomposition products on the surface, we believe nevertheless that the evolution of such gaseous products is followed by the formation of alkylgold species on the surface. A reasonable mechanism can be suggested for a continuously growing film of gold, as indicated in Scheme 2. The reactive

\footnotetext{
${ }^{1}$ Due to intensity of the molecular ion is lower $10 \%$, in Fig. 3 this product is presented by the fragmentary ion $\left[\mathrm{SCN}\left(\mathrm{C}_{2} \mathrm{H}_{5}\right)_{2}\right]^{+}$at $m / z 116$ as the most intensive.
}
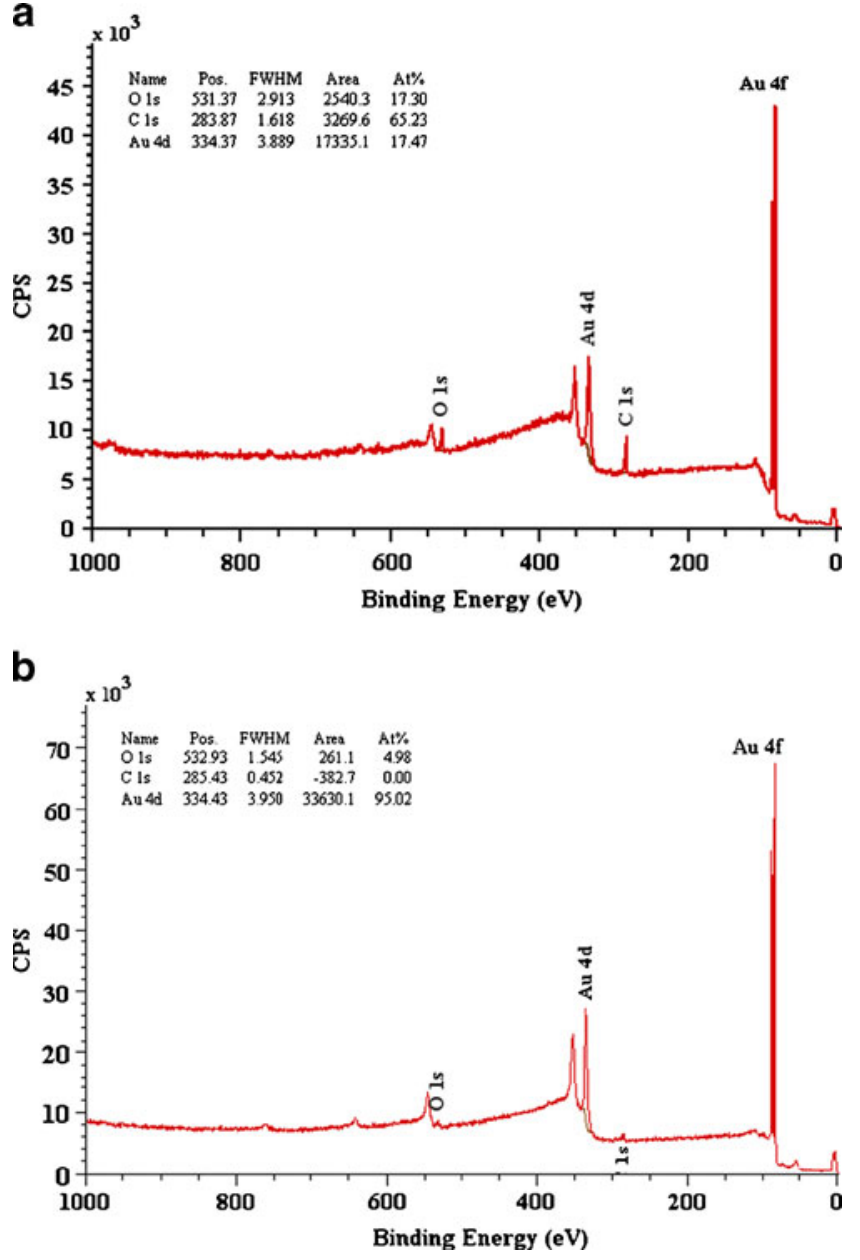

Fig. 5 General XPS spectra of the gold film before a and after $\mathrm{b} \mathrm{Ar}^{+}$ ions sputtering

surface of the growing gold film plays the role of the coordinatively unsaturated species and reacts directly with $\mathbf{1}$. Methylated and protonated ligands desorb from the surface and are pumped away, while alkylgold species remain bound to the surface (Eqs. 1 and 2). In due course, the association of two surface-bound alkylgold moieties and further dissociative desoprtion result in the evolution of saturated $\mathrm{C} 2-\mathrm{C} 4$ hydrocarbons into the gas phase and the formation of elemental gold (Eqs. 3, 4, and 5). Only propane is presented in Fig. 3 because the molecular ions of ethane and $n$-butane have low intensities and their mass spectra in the range of the fragmentary ions are superimposed on the mass spectra of other molecular species. ${ }^{2}$

Notice that $\beta$-hydride elimination is an event of low probability because no signals corresponding in particular to methane have been recorded. Thus, the reductive

\footnotetext{
$\overline{2}$ This means that the signal from the fragmentary ions consists of the signal produced by the ions of the same composition originating from other molecular precursor.
} 
coupling of alkyl fragments to give ethane, propane, and butane seems to be more probable. It is interesting that this conclusion is in agreement with the mechanism proposed for the decomposition of alkylgold(I) complexes [13, 14]. Based on these considerations, it may be concluded that the decomposition pathway favorable to obtain pure gold films is realized within the temperature range $210-240^{\circ} \mathrm{C}$.

With further temperature rise, a new gaseous product is observed, represented by the ion peak at $m / z 131$ which is attributed to $\left[\left(\mathrm{CH}_{3}\right) \mathrm{SCN}\left(\mathrm{C}_{2} \mathrm{H}_{5}\right)_{2}\right]^{+}$. This product is formed due to the cleavage of $\mathrm{C}-\mathrm{S}$ bond and the migration of $\mathrm{CH}_{3}$ group to the ligand. The maxima observed on the curves of protonated and methylated ligands at $215^{\circ} \mathrm{C}$ and $225^{\circ} \mathrm{C}$, respectively, together with the occurrence of the new product, indicate that the additional decomposition pathway appears at a temperature higher than $230^{\circ} \mathrm{C}$ (Scheme 3, Eq. 6). Similar to the previous pathways, further conversions of the surface intermediate $\mathrm{CH}_{3} \mathrm{AuS}$ occur by the "reductive coupling" mechanism. However, many possibilities of such a coupling exist due to the presence of alkylgold moieties on the surface formed in the course of previous reactions. Reactions 7 and 8 are confirmed by the evolution of ethyland propylmercaptans into the gas phase resulting in the formation of elemental gold. On the other hand, other reactions producing sulfur in the solid phase together with gold and the evolution of ethylmercaptane, ethane and propane into the gas phase may occur (Eqs. 9, 10, 11, and 12). Due to the similar composition of the gas phase, we are unable to say if these pathways are realized simultaneously or there is a prevailing reaction(s). However, based on the data of preliminary deposition experiments, one can suggest that the pathways in the mechanism of 1 decomposition producing only elemental gold in the solid phase are more likely. As to the possibility of reductive coupling of $\mathrm{CH}_{3} \mathrm{AuS}$ and alkylgold moieties with the formation of gaseous dialkylsulfides and dimeththyldisulfide and elemental gold (not shown in the Scheme), decomposition by these pathways did not proceed as no molecular ions of those gaseous products appeared in the mass spectra.

Our suggestions on the composition of the solid products of the precursor decomposition on the surface are supported by the results of preliminary CVD experiments. Figure 5 shows the XPS spectrum of gold nanostructured film prepared at $210^{\circ} \mathrm{C}$ with thickness $\sim 10 \mathrm{~nm}$ before and after etching with argon ions. XPS examination is shown in full range to represent the elemental composition of the surface. One can see that the gold film is free of sulfur that gives the signal within the region 160-164 eV (S2p) [26]. The lack of carbon after clearing the surface with argon ions indicates that carbon contamination is caused by ambient impurities (adventitious carbon). The observed oxygen signal is related to the substrate material. Thus, it may be concluded that pure gold films are deposited from 1 within temperature range $210-240^{\circ} \mathrm{C}$. To clear the question concerning possible contamination of the gold film with sulfur at $T>240^{\circ} \mathrm{C}$ according to Eqs. 9, 10, 11, and 12, additional deposition experiments are needed.

\section{Conclusion}

Volatile oxygen-, phosphorus-, and halogen-free dimethylgold(III)diethylditiocarbamate complex has the best combination of volatility, thermal, and storage stability among the volatile organogold compounds. According to the mechanism revealed from the studies of the temperature dependence of gas phase composition, the decomposition of the compound on the surface in vacuum follows three main pathways. The composition of the solid product was established by XPS analysis. Pure gold films are formed during chemical vapor deposition within the substrate temperature range $210-240^{\circ} \mathrm{C}$. From the preliminary deposition experiments, one can state that the investigated compound is a promising precursor to produce gold films by CVD.

Acknowledgment This work was supported by the EC under contract MC-IIF-39728 (ADALCO3).

Open Access This article is distributed under the terms of the Creative Commons Attribution License which permits any use, distribution and reproduction in any medium, provided the original author(s) and source are credited.

\section{References}

1. Bishop PT, Ashfield LJ, Berzins A, Boardman A, Buche V, Cookson J, Gordon RJ, Salcianu C, Sutton PA (2010) Printed gold for electronic applications. Gold Bulletin 43:181-188

2. Lee J-S (2010) Recent progress in gold nanoparticle-based nonvolatile memory devices. Gold Bulletin 43:189-199

3. He L, Shi ZQ (1996) Thin metal films deposited at low temperature for optoelectronic device application. J Vac Sci Technol A14:704 708

4. Morishige Y, Kishida S (1994) Thick gold-film deposition by high-repetition visible pulsed-laser chemical vapor deposition. Appl Phys A59:395-399

5. Armelles G, Gonzalez-Diaz J, Garcia-Martin A, Garcia-Martin J, Cebollada A, Gonzalez M, Acimovic S, CesarioJ QR, Badenes G (2008) Localized surface plasmon resonance effects on the magneto-optical activity of continuous $\mathrm{Au} / \mathrm{Co} / \mathrm{Au}$ trilayers. Optics Express 16(20):16104-16112

6. Liu J, Cankurtaran B, Wieczorek L, Ford MJ, Cortie M (2006) Anisotropic optical properties of semitransparent coatings of gold nanocaps. Adv Funct Mater 16(11):1457-1461

7. Prati L, Martra G (1999) New gold catalysts for liquid phase oxidation. Gold Bulletin 32(3):96-101

8. Murdoch M, Waterhouse GIN, Nadeem MA, Metson JB, Keane MA, Howe RF, Llorca J, Idriss H (2011) The effect of gold loading and particle size on photocatalytic hydrogen production from ethanol over $\mathrm{Au} / \mathrm{TiO} 2$ nanoparticles. Nat Chem 3:489-492. doi:10.1038/nchem.1048 
9. Palgrave RG, Parkin IP (2008) Surfactant directed chemical vapour deposition of gold nanoparticles with narrow size distributions. Gold Bulletin 41(1):66-69

10. Semyannikov P, Moroz B, Trubin S, Zharkova G, Pyryaev P, Smirnov M, Bukhtiyarov V (2006) Chemical vapor infiltration method for deposition of gold nanoparticles on porous alumina supports. J Struct Chem 47(3):458-464

11. Bessonov A, Morozova N, Gelfond N, Semyannikov P, Trubin S, Shevtsov Y, Shubin Y, Igumenov I (2007) Dimethylgold(III) carboxylates as new precursors for gold CVD. Surf Coatings Tech 201:9099-9103

12. Bessonov A, Morozova N, Gelfond N, Semyannikov P, Baidina I, Trubin S, Shevtsov Y, Igumenov I (2008) Synthesis, crystal structure and thermal behavior of dimethylgold(III) derivatives of salicylaldimine Schiff bases-novel precursors for gold MOCVD applications. J Organometallic Chem 693:2572-2578

13. Banaszak Holl M, Seidler P, Kowalczyk S, Read McFeely F (1994) Surface reactivity of alkylgold(I) complexes: substrateselective chemical vapor deposition of gold from $\operatorname{RAuP}\left(\mathrm{CH}_{3}\right)_{3}$ $\left(R=\mathrm{CH}_{2} \mathrm{CH}_{3}, \mathrm{CH}_{3}\right)$ at remarkably low temperatures. Inorg Chem 33:510-517

14. Tamaki A, Kochi JK (1973) Formation and decomposition of alkyl-gold(I) complexes. J Organometallic Chem 61:441-450. doi:10.1016/S0022-328X(00)86574-2

15. Tran PD, Doppelt P (2007) Gold CVD using trifluorophosphine gold(I) chloride precursor and its toluene solutions. J Electrochem Soc 154(10):D520-D525

16. Semyannikov PP, Grankin VM, Igumenov IK, Zharkova GI (1995) Mechanism of interaction of dimethylgold(III) chelates vapour with hot surface. J Phys II C5:213-220
17. Zharkova G, Baidina I, Igumenov I (2006) X-ray diffraction study of volatile complexes of dimethylgold(III) derived from symmetrical $\beta$ diketones. J Struct Chem 47(6):1117-1126

18. Zharkova G, Baidina I (2009) Volatile dimethylgold(III) $\beta$ iminovinylthionates: synthesis, structure, and properties. Russian J Coord Chem 35:36-41

19. Zharkova G, Baidina I, Yudanova T (2010) Synthesis, properties and crystal structures of volatile dimethylgold(III) complexes based on phenyl-containing $\beta$-diketones and $\beta$-iminoketone. Polyhedron 29:1049-1054

20. Bessonov A, Morozova N, Semyannikov P, Trubin S, Gelfond N, Igumenov I (2008) Thermal behaviour of dimethylgold(III) carboxylates. J Thermal Anal Calorimetry 92:751-755

21. Zharkova GI, Baidina IA, Igumenov IK (2007) Synthesis, properties, and structure of dimethylgold(III) complexes $\left[\left(\mathrm{CH}_{3}\right)_{2} \mathrm{AuI}\right]_{2}$ and $\left(\mathrm{CH}_{3}\right)_{2} \mathrm{AuS}_{2} \mathrm{CN}\left(\mathrm{C}_{2} \mathrm{H}_{5}\right)_{2}$. J Struct Chem 48(1):108-113

22. Semyannikov PP, Igumenov IK, Trubin SV, Chusova TP, Semenova ZI (2005) Thermodynamics of cromium acetylacetonate sublimation. Thermochim Acta 432:91-98

23. Bykov A, Tsarev S, Igumenov I (1995) High-temperature molecular beam source for the MSKh-6 mass spectrometer. Instrum Exp Technique 38(4):487-489

24. Gerbeleu NV, Indrichan KM (1984) Mass spectrometry of coordination compounds. Shtiints, Kishinev (in Russian)

25. Sysoev SV, Morozova NB, Zharkova GI, Igumenov IK, Semyannikov PP, Grankin VM (1998) Vapour pressure and thermoanalytical study of diethyldithiocarbamates of platinum metals. J Thermal Anal 53:87-96

26. Bourg M-C, Badia A, Lennox B (2000) Gold-sulfur bonding in 2D and 3D self-assembled monolayers: XPS characterization. J Phys Chem 104:6562-6567 